\title{
Body composition in aquatic organisms - A global data bank of relationships between mass, elemental composition and energy content
}

\author{
Thomas Brey ${ }^{\mathrm{a}, *}$, Corinna Müller-Wiegmann ${ }^{\mathrm{b}}$, Zora M.C. Zittier ${ }^{\mathrm{a}}$, Wilhelm Hagen ${ }^{\mathrm{b}}$ \\ a Alfred Wegener Institute for Polar and Marine Research, P.O. Box 120161, 27515 Bremerhaven, Germany \\ ${ }^{\mathrm{b}}$ Marine Zoology, University of Bremen, P.O. Box 330440, 28334 Bremen, Germany
}

\section{A R T I C L E I N F O}

\section{Article history:}

Received 1 October 2009

Received in revised form 12 April 2010

Accepted 3 May 2010

Available online 10 May 2010

\section{Keywords:}

Body Composition

Conversion Factor

C/N/P Ratio

Energy Content

\begin{abstract}
A B S T R A C T
We introduce a global data bank on body composition of aquatic organisms that is available at http://www. thomas-brey.de/science/virtualhandbook. It covers ratios between body mass (wet, dry, ash free dry mass), body composition (protein, lipid, carbohydrate), macro-elements (C, N, P) and energy content (J). Sofar, data for 3158 different taxa (animals, plants, bacteria) were collected from 725 different sources. The principal purpose of the data bank is mining for conversion factors, as necessary in ecological studies that require a common energetic currency. The data bank can be used to explore general ecological principles, too: among all animals, carnivorous swimmers have the highest energy density, presumably an across-taxon selection for propulsion power and handling force. Plants and animals do not only differ in their $\mathrm{C} / \mathrm{N}$ and $\mathrm{C} / \mathrm{P}$ ratios, but these ratios change with temperature in opposite directions. In plants, $\mathrm{C} / \mathrm{N}$ and $\mathrm{C} / \mathrm{P}$ increase with temperature, most likely a response to the higher levels of $\mathrm{N}$ and $\mathrm{P}$ in polar waters. In animals $\mathrm{C} / \mathrm{N}$ and $\mathrm{C} / \mathrm{P}$ decrease with temperature, an indicator for selection towards lower activity and larger lipid stores in polar animals.
\end{abstract}

(C) 2010 Elsevier B.V. All rights reserved.

\section{Introduction}

Body composition of aquatic organisms is characterized in many ways. Anybody is composed of water, inorganic matter and a variety of organic compounds. Accordingly, the most basic characterization of body composition is by water and ash content. The share of major organic macromolecule classes, i.e. proteins, lipids, and carbohydrates, is another commonly used descriptor of body composition. Detailed analysis of macromolecule inventory focuses on fatty acids, very often in relation to food web and alimentation studies (e.g. Graeve et al., 2005, Nyssen et al., 2005). Amount of and ratios between the major bioreactive elements carbon, nitrogen and phosphorus play an essential role in nutrient cycles and nutritional constraints in food webs (ecological stoichiometry, see e.g. Hessen et al., 2002, McGroddy et al., 2008, Liess \& Hillebrand, 2006). Finally, since Lindeman (1942) energy content is seen as the basic "currency" in ecosystems that determines the energetic "value" of a trophic transfer.

An organism's body composition is far from being static but may vary with season in both plants (e.g. Altamirano et al., 2000, Villares \& Carballeira, 2003) and animals (e.g. Lasta et al., 2001, Pinkard et al., 2001, Finstad et al., 2003); with temperature (e.g. Koskela et al., 1997, Sogard et al., 2004); with nutrient availability in plants (e.g. Guerrini et al., 2000); with diet and nutritional status in animals (e.g. Sipaúba-Tavares et al., 2001, Liu et al., 2004, McLeod et al., 2004, Zhou et al., 2004); with

\footnotetext{
* Corresponding author. Fax: +494714831 1918.

E-mail address: Thomas.Brey@awi.de (T. Brey).
}

population developmental stage in microalgae (Gatenby et al., 2003); or with developmental stage, age and sex in animals (e.g. Jonsson \& Jonsson, 1998, Villar-Argaiz et al., 2002, Raymond et al., 2004).

Most previous reviews and compilations of body composition data focused either on specific relationships such as energy content, or on differences between taxa in a taxonomic, life-style related or geographic subset of aquatic organisms (e.g. Bailey \& Robison, 1986, Wacasey \& Atkinson, 1987, Brey et al., 1988, Steimle \& Terranova, 1988, Dauvin \& Joncourt, 1989, Ricciardi \& Bourget, 1998, Roslin, 2003, Cauffopé \& Heymans, 2005). Moreover, most of these compilations are closed and static, i.e. no new data are added, and re-analysis is difficult because the basic data are available as hardcopy at best.

We present a data bank of conversion factors in aquatic organisms that (i) is open, i.e. further data can be added any time, (ii) is interactive, i.e. the user can search for particular taxa using specific filters, and (iii) aims at all-taxa, all-systems, all-factors coverage. On the one hand we intend to introduce a working tool for applied aquatic ecology, particularly for trophic and energy flow studies that require standardized units of body mass or energy content. On the other hand, we demonstrate how this tool can be applied to more general questions, too, by exploring whether evolutionary adaptation led to life-style related differences in certain measures of body composition in aquatic organisms. In particular, we analyze (i) whether body composition of aquatic animals differs between mobility modes or between alimentation modes, and (ii) whether C: $\mathrm{N}: \mathrm{P}$ stoichiometry of aquatic organisms differs between alimentation modes. 